\title{
Biosynthesis and characterization of titanium dioxide nanoparticles using pithecellobium dulce and lagenaria siceraria aqueous leaf extract and screening their free radical scavenging and antibacterial properties
}

\author{
S. Kalyanasundharam*, M. Jeevan Prakash \\ * Department of Chemistry, Poompuhar College(Autonomous), Melaiyur, Tamilnadu, India-609 107 \\ *E-mail address: skalyanasundharam@gmail.com
}

Keywords: Biosynthesis, titanium dioxide

\begin{abstract}
The recent development and implementation of new technologies have led to new era, the nano-revolution which unfolds role of plants in bio and green synthesis of nanoparticles which seem to have drawn quite an unequivocal attention with a view of synthesizing stable nanoparticles. In this present work, we have compared titanium dioxide nanocrystals synthesized by both chemical method and biological method from Titanium tetra isopropoxide as precursor. The biological method was performed by using the aqueous plant extract of Pithecellobium dulce and Lagenaria siceraria. The synthesized nanocrystals were characterized by FTIR Spectroscopy, Scanning Electron Microscopy (SEM), Energy Dispersive Xray (EDAX), Transmission Electron Microscope (TEM) and X-ray diffraction (XRD) techniques and also Antioxidant assay and antimicrobial test were performed to evaluate its biological behaviour. The nanocrystals synthesized by biological method were found to have higher antioxidant potential, antimicrobial activity than chemically synthesized.
\end{abstract}

\section{INTRODUCTION}

Biological synthesis of nanoparticles by plant extract is at present under exploitation for the reason that to develop environmentally benign nanoparticles synthesis to avoid adverse effects in biomedical applications (M. Sundrarajan et al2011). The manipulation of matter on an atomic, molecular, and supramolecular scale. The earliest, widespread description of nanotechnology, Nanoparticles are usually $\leq 100 \mathrm{~nm}$ in each spatial dimension or less have attracted great attention due to their unusual and fascinating properties, Nanoparticle research is currently an area of intense scientific interest due to a wide variety of potential applications in biomedical, optical and electronic fields and applications advantageous over their bulk counterparts [M. C. Daniel et al, 2004]. Nanoparticles are classified primarily into two types, viz organic and inorganic nanoparticles. The nanoparticles of carbon are called the organic nanoparticles. Magnetic nanoparticles, noble metal nanoparticles (platinum, gold and silver) and semiconductor nanoparticles (titanium dioxide, zinc oxide and zinc sulfide) are classified as inorganic nanoparticles (Kathiresan et al, 2013).

Titanium dioxide $\left(\mathrm{TiO}_{2}\right)$, an important semiconductor nanoparticle has been interesting attention for its wide range of applications, such as electronics, optics, optoelectronics, transparent, UV-light emitters, piezoelectric devices, chemical sensors, spintronics. Further, $\mathrm{TiO}_{2} \mathrm{NPs}_{\text {exhibit }}$ size and shape-dependent properties which are of interest for applications ranging from biosensing and catalysts to optics, antimicrobial activity, computer transistors, electrometers, chemical sensors, and wireless electronic logic and memory schemes. These particles also have many applications in different fields such as medical imaging, nanocomposites, filters, drug delivery, and hyperthermia of tumors (D. Bhattacharya et al, 2005; D. Goodsell, 2004; R. Paull et al, 2003; O. V. Salata, 2004). Nanoparticles are usually 0.1 to $1000 \mathrm{~nm}$ in each spatial dimension and are commonly synthesized using two strategies: top down and bottom up. In top-down approach, the bulk materials are 
gradually broken down to nanosized materials, whereas in bottom-up approach, atoms or molecules are assembled to molecular structures in nanometer range. Bottom-up approach is commonly used for chemical and biological synthesis of nanoparticles, by chemical methods leads to the presence of some toxic chemical species adsorbed on the surface that may have adverse effects in medical applications. Due to the obvious disadvantages of the chemical reduction method, a biological synthesis of nanomaterials is an important aspect of nanotechnology. There is a growing need to develop simple, low-cost, eco-friendly and size control approaches for the synthesis of metal nanoparticles. Biological route synthesis of nanoparticles has received much focused attention from researchers in order to elucidate the mechanism of synthesis. To circumvent this many biological systems like bacteria [Kumar CG et al, 2011], fungi [Rodriques AG et al, 2012], yeast, cyanobacteria, actinomycetes and plants have been used. But the best one appears to be the use of plants.

However, review of literature revealed that the synthesis of metal oxides and semiconductors nanoparticles using plant has been explored in number of few literatures [Mahdavi M, 2013], which aroused our interest in the present study the synthesis of $\mathrm{TiO}_{2}$ nanoparticles by utilizing the aqueous leaf extract of P. dulce and Lagenaria siceraria. Pithecellobium dulce (P. dulce) Benth (Fabaceae) is a small to medium sized, evergreen, spiny tree, up to $18 \mathrm{~m}$ height, native of tropical America and cultivated throughout the plains of India and in the Andamans. It is known as 'Kodukkapuli' in Tamil. The bark of the plant is reported to be used as astringent in dysentery, febrifuge and it is also used in dermatitis and eye inflammation. In traditional medicine practice, the leaves of P. dulce are used for the treatment to fearache, leprosy, pepticulcer, toothache, venereal diseases and also act as emollient, anodyne, larvicidic and abortifacient, and antidiabetic properties in folk medicine. The presences of steroids, saponins, lipids, phospholipids, glycosides, glycoli. And the Lagenaria siceraria leaf, Bottle gourd (Lagenaria siceraria (Mol.) standley, family Cucurbitaceae) commonly called as Dudhi or Ghiya is widely cultivated in the tropical and subtropical regions of the world, Lagenaria siceraria, which has diuretic and anti-swelling effects, is used as food. A decoction of Lagenaria siceraria is employed in the treatment of anasarca, ascites and beriberi [Deshpande et al., 2008].So far, there is no report on the synthesis of $\mathrm{TiO}_{2}$ by utilizing the aqueous leaf extract of Pithecellobium dulce and Lagenaria siceraria. Hence, the present study involves the synthesis and characterization of Pithecellobium dulce and leaf mediated $\mathrm{TiO}_{2}$ and evaluating the anti-bacterial effect of biosynthesized $\mathrm{TiO}_{2}$ in comparison to chemically synthesized $\mathrm{TiO}_{2}$ and plant extract against human pathogens such as gram-positive and gram- negative bacteria.

\section{MATERIAL AND METHODS}

\subsection{Materials}

Titanium tetraisopropoxide [Ti $\left.\left(\mathrm{OCH}\left(\mathrm{CH}_{3}\right)_{2}\right)_{4}\right]$, Isopropanol $\left(\mathrm{C}_{3} \mathrm{H}_{7} \mathrm{OH}\right)$, Acetic acid $\left(\mathrm{CH}_{3} \mathrm{COOH}\right)$ and ethanol were purchased from Sigma Aldrich, India. All the chemicals were used without any further purification. Nutrient media used for antibacterial activity were purchased from Hi-Media, Mumbai, India. All aqueous solutions were prepared using de-ionized water. All glass wares were cleaned with chromic acid followed by thorough washing with de-ionized water and then acetone for prior use. 

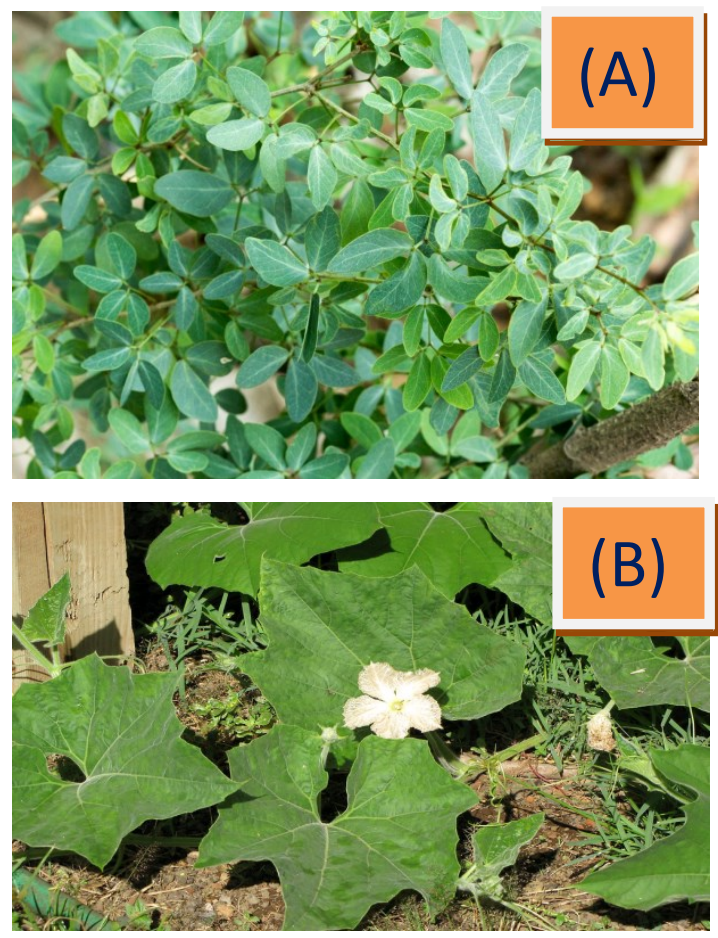

Figure 1: Plant Images of (A) Pithecellobium dulce leaf (B) Lagenaria siceraria leaf

\section{Preparation of aqueous leaf extract}

Lagenaria siceraria and Pithecellobium dulce leaf were collected from rural areas of Chidambaram, Tamil Nadu, India. Leafs were washed thoroughly with tap water and dried in the shade. Dried leafs were cut into small pieces and ground coarsely using pulverizer. Soxhlet extraction was then performed to obtain the crude aqueous extract which is stored in the refrigerator for further use.

\section{Synthesis of titanium dioxide nanocrystals \\ By chemical method}

$\mathrm{TiO}_{2}$ nanocrystals were prepared by the sol gel technique. Metal precursor Titanium tetraisopropoxide $(2 \mathrm{~mL})$ was added to solvents Isopropanol $(2 \mathrm{~mL})$ and acetic acid $(1 \mathrm{~mL})$. It was rapidly stirred at room temperature and distilled water was added drop wise to obtain sol gel transformation. It was then air dried and calcined at $450^{\circ} \mathrm{C}$ for 30 minutes to obtain nanocrystalline $\mathrm{TiO}_{2}$.

\section{Biosynthesis of $\mathrm{TiO}_{2}$ nanoparticles}

For the synthesis of titanium dioxide nanoparticles, the Erlenmeyer flask containing $0.4 \mathrm{M}$ of titanium tetraisoproxide in ethanolic leaf extract was reacted under stirring at $50^{\circ} \mathrm{C}$. After four hours of continuous stirring, the formed titanium dioxide nanoparticles was acquired by centrifugation at $10000 \mathrm{rpm}$ for 15 minutes. Then the centrifuged particles were washed with ethanol and again subjected to centrifugation at 5000rpm for 10 minutes. Separated titanium dioxide nanoparticles were dried and grinded to calcinate at $500^{\circ} \mathrm{C}$ in muffle furnace for about 3 hours. The calcined titanium dioxide nanopowder was used for further analytical techniques.

\section{ANALYTICAL METHODS}

High resolution Scanning Electron Microscopy (HRSEM) and Elementary Dispersive X-ray (EDX) analysis experiments were carried out on a FEI Quanta FEG 200 instrument with EDX analyzer facility at $258 \mathrm{C}$. TEM images of metal oxide nanoparticles were obtained using a transmission electron microscope (PHILIPS CM200 model) at an Operating voltages : $20-200 \mathrm{kV}$ Resolution :2.4 $\mathrm{A}^{\mathrm{o}}$. XRD spectra was recorded on the X'PERT PRO model X-ray diffractometer 
from Pan Analytical instruments operated at a voltage of $40 \mathrm{kV}$ and a current of $30 \mathrm{~mA}$ with $\mathrm{Cu} \mathrm{Ka}$ radiation.Fourier transform infrared spectroscopy. FT-IR spectroscopic studies were carried out to identify the possible functional groups in the leaf extract responsible for capping leading to efficient stabilization of the $\mathrm{TiO}_{2}$. The FT-IR spectra of powdered $\mathrm{TiO}_{2}$ were mixed with $\mathrm{KBr}$ pellets and are recorded in the 4,000-400 $\mathrm{cm}^{-1}$ range on a Shimadzu FTIR-8400s

\section{Antimicrobial activity}

In the present study, in vitro antimicrobial activities were carried out by the using of diskdiffusion method [H.W. Seely et al, 1975; A. L. Barry, 1976]. This method followed the following procedure: First of all, Petri plates were prepared with $20 \mathrm{~mL}$ of sterile Muller Hinton Agar . Then, the $24 \mathrm{~h}$ prepared test cultures of inoculums were swabbed on the top of the solidified media and allowed to dry for $10 \mathrm{~min}$. chemically and biosynthesized $\mathrm{TiO}_{2}$ nanoparticles impregnated disks at the concentrations of $50 \mu \mathrm{g} / \mathrm{mL}$ for bacteria was placed aseptically on sensitivity plates with appropriate controls. The loaded disks were placed on the surface of the medium and left for $30 \mathrm{~min}$ at room temperature for compound diffusion. Negative control was prepared using respective solvent. Ciprofloxacin $(5 \mu \mathrm{g} / \mathrm{disk})$ was used as positive control for bacteria. All the plates were then incubated at $37^{\circ} \mathrm{C}$. The sensitivity was recorded by measuring the clear zone of growth inhibition on agar surface around the disks in millimeter.

\section{Free radical scavenging activity}

Biosynthesized Au-NPs and S. nigrum were tested for the scavenging effect on DPPH radical according to the method of [Blois, 1958] Different concentrations (50, 100 and 150_L) of S. nigrum and biosynthesized Au-NPs were added, in equal volume, to $0.1 \mathrm{mM}$ metabolic DPPH solution. The reaction mixture was incubated for $30 \mathrm{~min}$ at room temperature under shaking condition and the absorbance was recorded at $517 \mathrm{~nm}$. The synthetic antioxidant butyl hydroxyl toluene (BHT) was used as positive control. All determinations were performed in triplicate. The DPPH radical scavenging activity (RSA) was expressed in percentage of inhibition using the following formula.

$$
\mathrm{RSA}=\frac{\mathrm{A}_{\text {control }}-\mathrm{A}_{\text {sample }}}{\mathrm{A}_{\text {control }}} \times 100
$$
sample.

where $\mathrm{A}_{\text {sample }}$ is the absorbance of the blank control and $\mathrm{A}_{\text {control }}$ is the absorbance of the test

In this study we have synthesized $\mathrm{TiO}_{2}$ nanoparticles from titanium tetraisoproxide solution using Lagenaria siceraria and Pithecellobium dulce leaf extract. The green synthesised $\mathrm{TiO}_{2}$ nanoparticles were characterised using XRD, SEM, EDX and FTIR and investigated for antibacterial activity, in comparison with chemically synthesized $\mathrm{TiO}_{2}$ nanoparticles.

\section{RESULTS AND DISCUSSION}

\section{Powder X-ray diffraction (XRD)}

The XRD pattern of $\mathrm{TiO}_{2}$ nanoparticles obtained using leaf extract of Lagenaria siceraria and Pithecellobium dulce and chemically synthesized $\mathrm{TiO}_{2}$ nanoparticles are shown in Figure $2 \mathrm{a}, 2 \mathrm{~b}$ and 2c. In the green synthesized $\mathrm{TiO}_{2}$ using Pithecellobium dulce show slightly broad diffraction peaks emerge at $2 \theta$ angles of $25.41^{\circ}, 37.77^{\circ}, 47.82^{\circ}, 54.52^{\circ}$ and $62.92^{\circ}$ corresponds to Bragg's reflection from 101, 004, 200, 105 and 204 crystal planes(JCPDS files \# 21-1272), suggesting the anatase phase of nanocrystalline $\mathrm{TiO}_{2}$ this also confirm with angles $25.47^{\circ}, 37.87^{\circ}, 48.02^{\circ}, 54.62^{\circ}$ and $63.07^{\circ}$ obtained from synthesized $\mathrm{TiO}_{2}$ nanoparticles from leaf extract of Lagenaria siceraria (Vijayalakshmi, R et al, 2012) . 

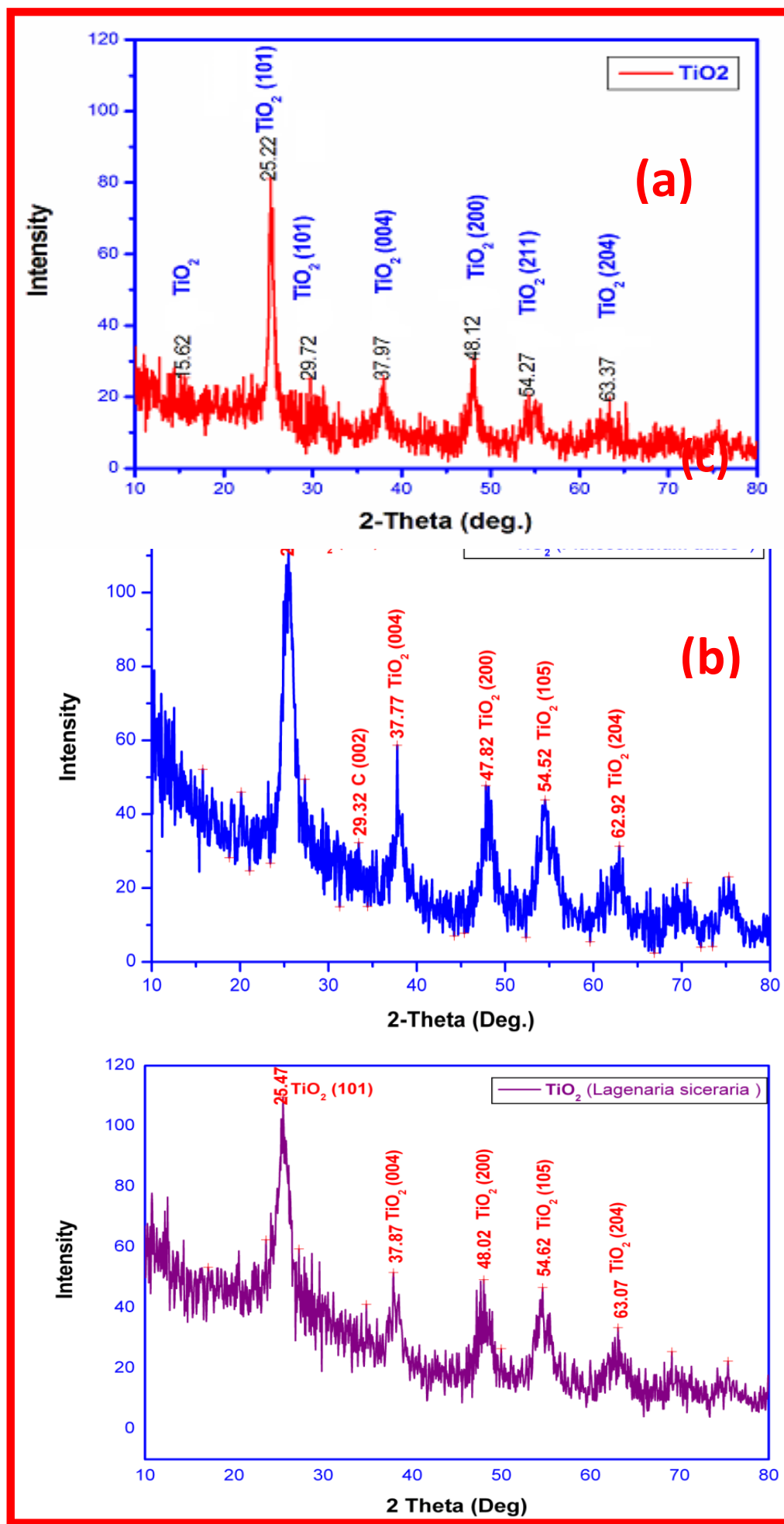

Fig.2. XRD patterns of (a) Pithecellobium dulce leaf Extract synthesized $\mathrm{TiO}_{2}$ (b) Lagenaria siceraria leaf Extract synthesized $\mathrm{TiO}_{2}$ (c) Chemically synthesized $\mathrm{TiO}_{2}$ 
In the chemically synthesized $\mathrm{TiO}_{2}$ also, sharp diffraction peaks emerge at $2 \theta$ angles $25.22^{\circ}$, $37.97^{\circ}, 47.12^{\circ}, 54.27$ and $63.37^{\circ}$ corresponds to Bragg's reflection from 101, 004, 200, 105 and 204 crystal planes. The result of XRD analysis confirms the presence of $\mathrm{TiO}_{2}$ nanoparticles in the green and chemically synthesized sample. The XRD peaks of green synthesized $\mathrm{TiO}_{2}$ nanoparticles obtained using leaf extract of Lagenaria siceraria and Pithecellobium dulce and chemically synthesized $\mathrm{TiO}_{2}$ nanoparticles differ in the broadening and intensity. The diffraction peak of the green synthesised $\mathrm{TiO}_{2}$ nanoparticles is slightly broadened, whereas the peak of chemically synthesized $\mathrm{TiO}_{2}$ nanoparticles is comparatively sharp. Thus, the broadening of XRD peak of green synthesized $\mathrm{TiO}_{2}$ nanoparticles observed in our study confirms the size reduction. The XRD peak of chemically synthesized $\mathrm{TiO}_{2}$ nanoparticles is sharp, thus indicating that their size is still larger than the green synthesized $\mathrm{TiO}_{2}$ nanoparticles (Naheed Ahmad et al. 2012).

The average crystalline size $(\mathrm{L})$ of the $\mathrm{TiO}_{2}$ nanoparticles can be calculated from the DebyeScherrer formula, $\mathrm{L}=0.891 / \mathrm{b} \cos \theta$ where $\mathrm{L}$ is the crystalline size (in $\mathrm{nm}$ ), 1 is the wavelength (in $\mathrm{nm}), \mathrm{b}$ is the full width at half maximum intensity (FWHM-in radian), and $\theta$ is the Bragg diffraction angle . The average crystalline size of $\mathrm{TiO}_{2}$ obtained from leaf extract of Pithecellobium dulce , Lagenaria siceraria and chemically synthesized was figured out to be about $7.5 \mathrm{~nm}, 8.6 \mathrm{~nm}$ and $18.5 \mathrm{~nm}$. As can be understood, these values are very close to the TEM value.

\section{FT-IR}

Fig. $3 \mathrm{a}, 3 \mathrm{~b}$ and $3 \mathrm{c}$ shows the FT-IR spectrum of leaf Extract synthesized $\mathrm{TiO}_{2}$ of Pithecellobium dulce, leaf Extract synthesized $\mathrm{TiO}_{2}$ of Lagenaria siceraria and chemically synthesized $\mathrm{TiO}_{2}$ nanoparticles. In green synthesized $\mathrm{TiO}_{2}$ nanoparticles from leaf extract of 


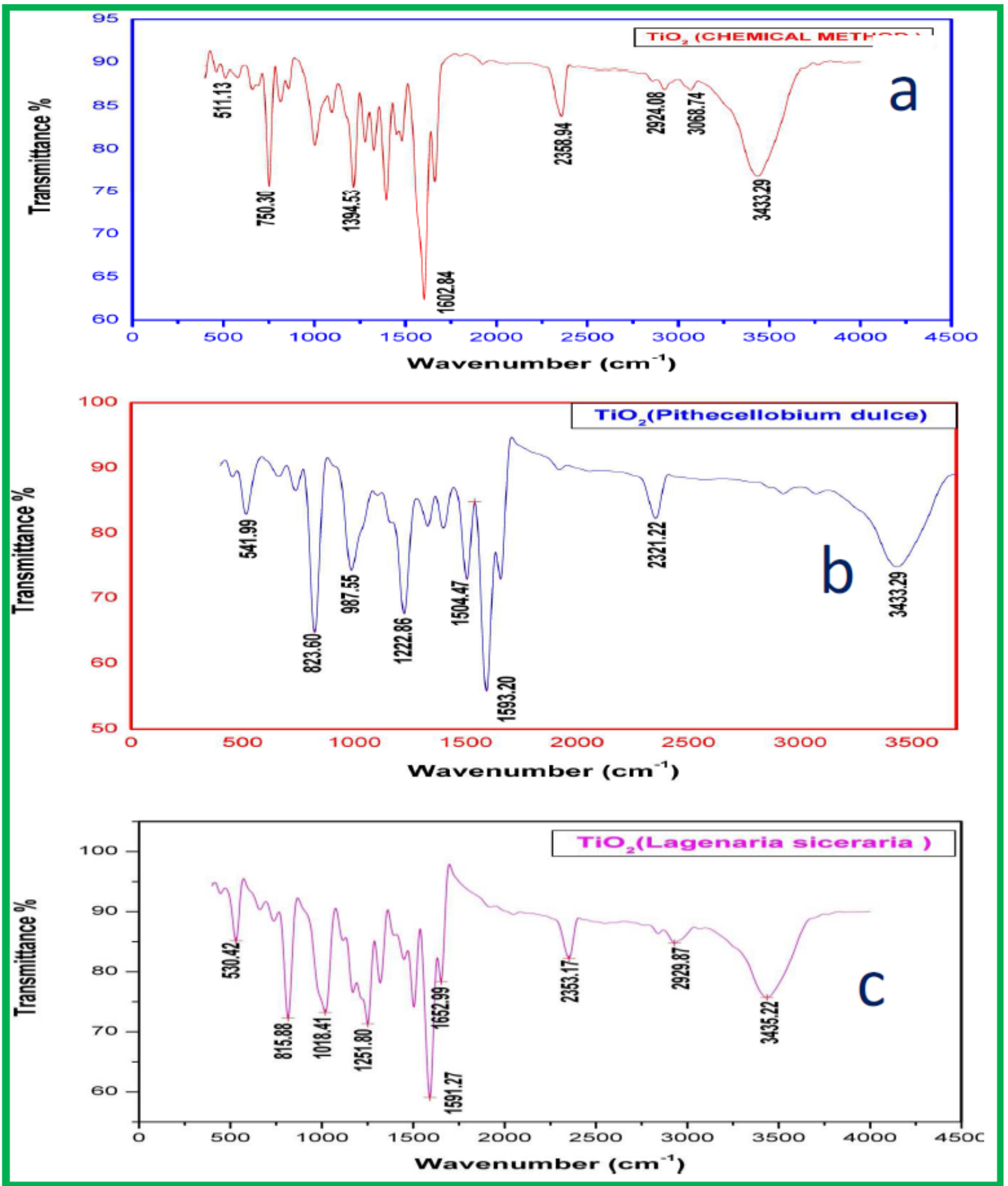

Figure 3: (a) IR Spectrum of Pithecellobium dulce leaf Extract synthesized $\mathrm{TiO}_{2}$ (b) Lagenaria siceraria leaf Extract synthesized $\mathrm{TiO}_{2}$ (c) Chemically synthesized $\mathrm{TiO}_{2}$

Pithecellobium dulce shows IR spectrum covers an absorption band at $3433.29 \mathrm{~cm}^{-1}$, $2321.22 \mathrm{~cm}^{-1}, 1593.20 \mathrm{~cm}^{-1}, 1504.47 \mathrm{~cm}^{-1}, 1222.86 \mathrm{~cm}^{-1}, 823.60 \mathrm{~cm}^{-1}$ and $541.99 \mathrm{~cm}^{-1}$. IR spectrum of Lagenaria siceraria shows absorption band at $3435.22 \mathrm{~cm}^{-1}, 2353.17 \mathrm{~cm}^{-1}, 1591.27 \mathrm{~cm}^{-}$ $1,1251.80 \mathrm{~cm}^{-1}, 815.88 \mathrm{~cm}^{-1}$ and $530.45 \mathrm{~cm}^{-1}$. Strong absorption peaks at 3433.29 and $3435.22 \mathrm{~cm}^{-}$ ${ }^{1}$ refers to O-H stretch of water and phenolic compounds which are present in the FTIR spectrum of Pithecellobium dulce and Lagenaria siceraria extract too that indicates a strong interaction between leaf extracts and green synthesized $\mathrm{TiO}_{2}$ nanocrystals. The peak at 1593.20 and $1591.27 \mathrm{~cm}-1$ 
shows the aryl substituted $\mathrm{C}=\mathrm{C}$ stretching of Pithecellobium dulce and Lagenaria siceraria leaf extract. The intense peak between 823,815 and $541,530 \mathrm{~cm}^{-1}$ describes the Ti-O stretching bands of Pithecellobium dulce and Lagenaria siceraria leaf extract synthesized $\mathrm{TiO}_{2}$ nonmaterial. At the same time chemically synthesized $\mathrm{TiO}_{2}$ nanoparticles a broad absorption peak around $3433 \mathrm{~cm}^{-1}$ is due to the stretching vibration of $-\mathrm{OH}$ groups on the $\mathrm{TiO}_{2}$ surface. The broad band from 511 and $750 \mathrm{~cm}^{-1}$ were ascribed to the strong stretching vibrations of $\mathrm{Ti}-\mathrm{O}-\mathrm{Ti}$ bonds. In IR study, the phytochemicals present in the crude extract of the flower may interact with the surface of the $\mathrm{TiO}_{2}$ nanoparticles, thus forming a cap. Phenol and amide capped nanoparticles were reported to possess significantly higher biomedical activities than uncapped nanoparticles. Therefore, the green synthesized $\mathrm{TiO}_{2}$ nanoparticles may possess potential biomedical benefits than uncapped $\mathrm{TiO}_{2} \mathrm{Nano}$ particles (Thiyagarajan Devasena et al,2014)

\section{SEM AND EDX}

Fig. 4a, $4 \mathrm{~b}$ and $4 \mathrm{c}$ shows the SEM images of biostabilised $\mathrm{TiO}_{2}$ nanoparticles obtained using Pithecellobium dulce and Lagenaria siceraria leaf extract and chemical route respectively. The leaf extract mediated synthesized $\mathrm{TiO}_{2}$ nanoparticles show monodispersity without aggregation when compared to that of chemically synthesized $\mathrm{TiO}_{2}$ nanoparticles. I 


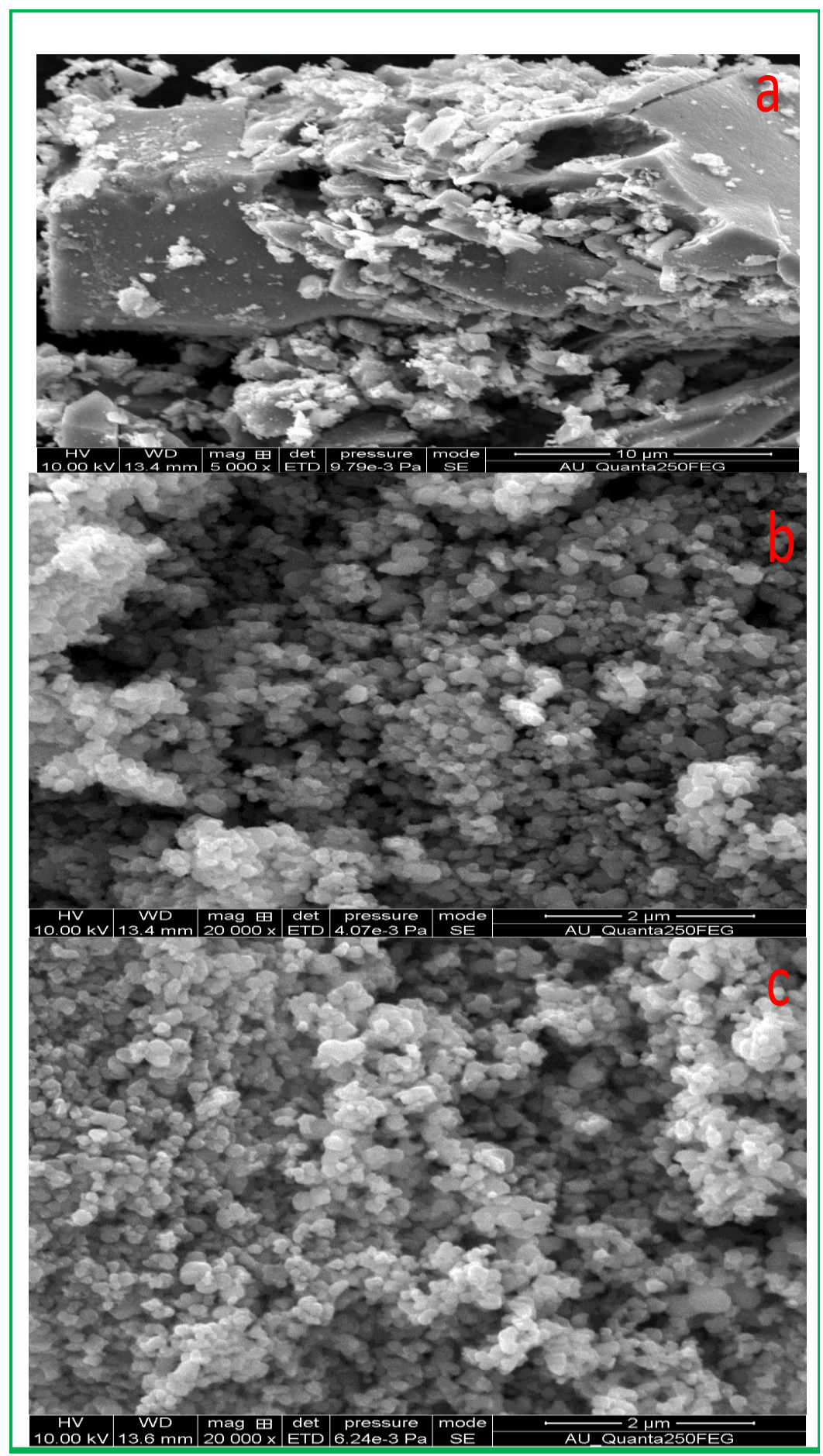

Figure 4: (a) SEM Images of Pithecellobium dulce leaf Extract synthesized $\mathrm{TiO}_{2}$ (b) Lagenaria siceraria leaf Extract synthesized $\mathrm{TiO}_{2}(c)$ Chemically synthesized $\mathrm{TiO}_{2}$

This is due to the capping of $\mathrm{TiO}_{2}$ nanoparticles with the compounds present in the Pithecellobium dulce and Lagenaria siceraria leaf extract. Previous report that plant phytochemicalfunctionalized nanoparticles are disaggregated and stable with good dispersibility (Archana et al. 2012). EDX spectrum of green synthesized $\mathrm{TiO}_{2}$ shown in Figure $6 \mathrm{a}, 6 \mathrm{~b}$ and $6 \mathrm{c}$, in which peaks of titanium and oxygen elements proves $\mathrm{TiO}_{2} \mathrm{NPs}$ prepared is essentially free from impurities.

\section{TEM}

Transmission electron microscopy was used to examine the morphological characteristics of the $\mathrm{TiO}_{2}$ nanoparticles obtained using Pithecellobium dulce and Lagenaria siceraria leaf extract and chemical route respectively (Figure 5a,5b,5c). TEM images showed that sample was composed of agglomerated and isolated particles and it reveals that small particles aggregate into secondary particles because of their extremely small dimensions and high surface energy. Therefore the diameter and the size distribution of the nanoparticles are difficult to be determined precisely by 
simply viewing the TEM image. The TEM image of the $\mathrm{TiO}_{2}$ sample obtained from Pithecellobium dulce (Figure 5a) shows the presence of spherical shape with average diameter of $\sim 6.3 \mathrm{~nm}$. The morphology of the $\mathrm{TiO}_{2}$ sample synthesized from Lagenaria siceraria is also spherical shape (Figure $5 b)$. These particles have an average diameter of about $6.6 \mathrm{~nm}$. The morphology of the $\mathrm{TiO}_{2}$ sample synthesized from chemical method spherical and hexagonal shape (Figure 5c), but the particles are greater than those found green method. These particles have an average diameter of about $14.4 \mathrm{~nm}$. The TEM images of both samples show large agglomeration of the $\mathrm{TiO}_{2}$ particles.

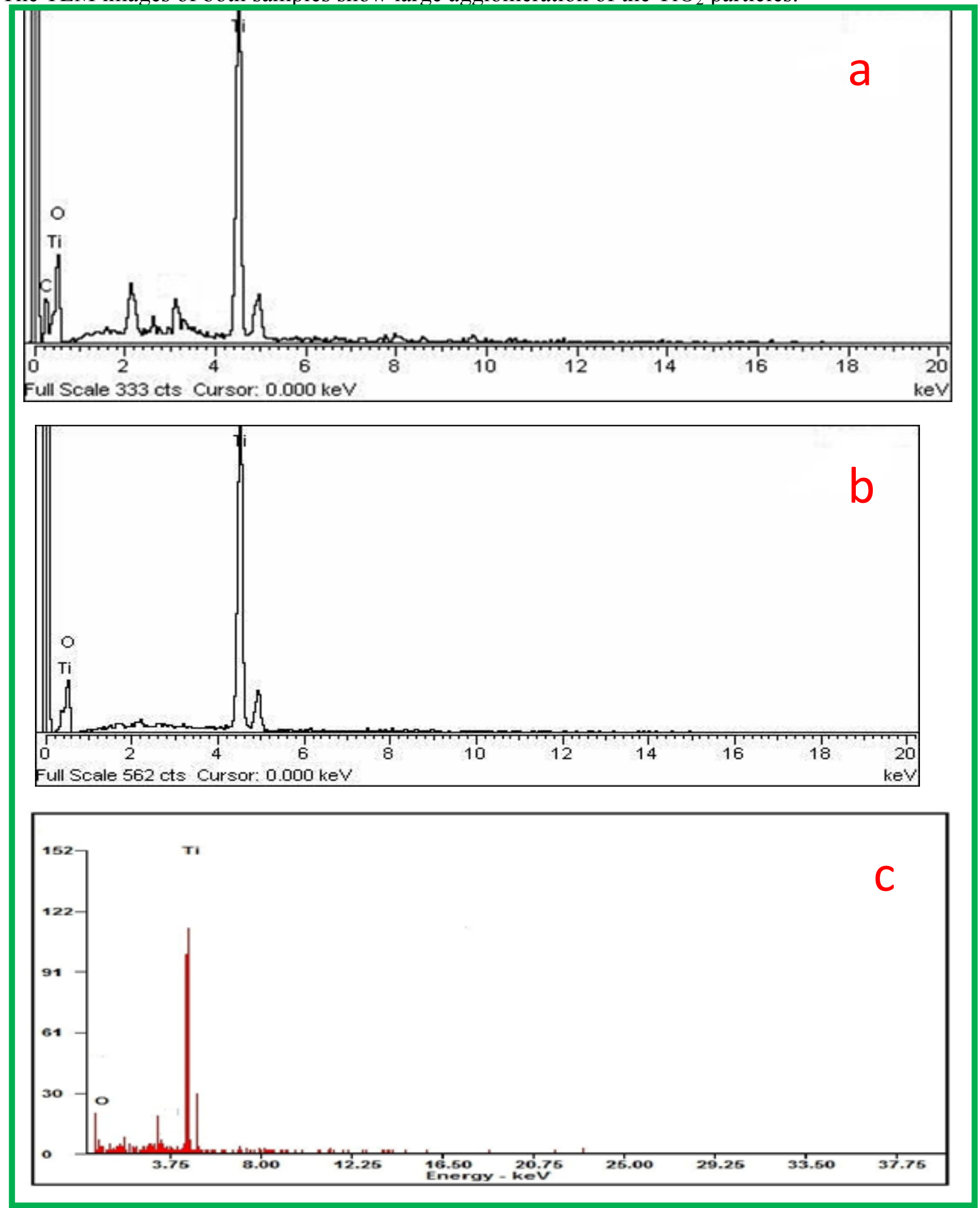

Figure 6: (a) EDX Spectrum of Pithecellobium dulce leaf Extract synthesized $\mathrm{TiO}_{2}$ Lagenaria siceraria leaf Extract synthesized $\mathrm{TiO}_{2}$ (c) Chemically synthesized $\mathrm{TiO}_{2}$ 


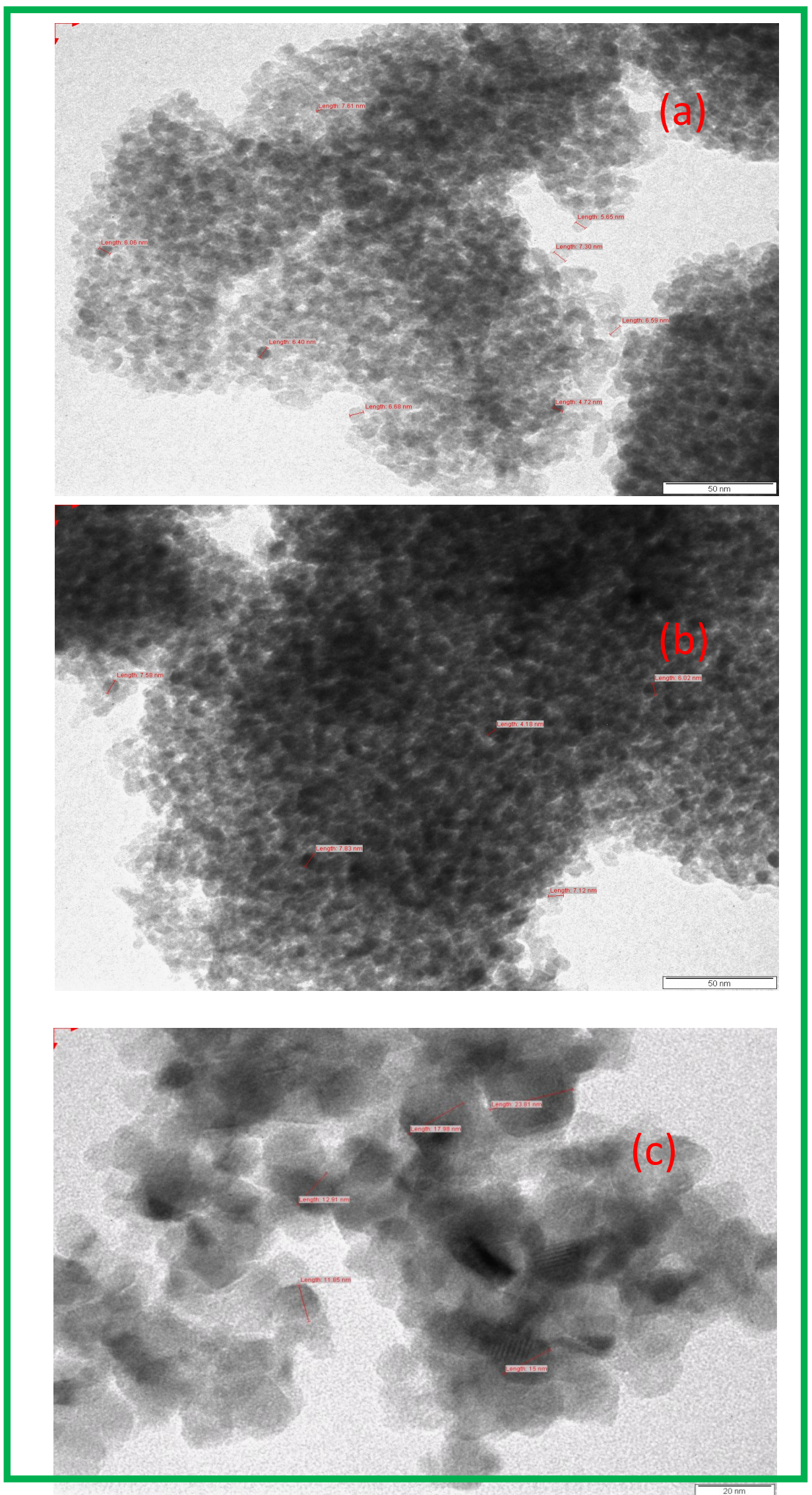

Figure 5: (a) TEM Images of Pithecellobium dulce leaf Extract synthesized $\mathrm{TiO}_{2}$ (b) Lagenaria siceraria leaf Extract synthesized $\mathrm{TiO}_{2}$ (c) Chemically synthesized $\mathrm{TiO}_{2}$ 


\section{ANTIBACTERIAL PROPERTIES}

Antibacterial activity results revealed that Pithecellobium dulce and Lagenaria siceraria leaf extract mediated synthesized $\mathrm{TiO}_{2}$ nanoparticles acted as excellent antibacterial agents against both Gram-positive and Gram-negative bacteria when compared chemically synthesized $\mathrm{TiO}_{2}$ nanoparticles. It is clear from the XRD and SEM results that leaf extract mediated synthesized $\mathrm{TiO}_{2}$ nanoparticles are smaller in size compared to chemically synthesized $\mathrm{TiO}_{2}$ nanoparticles. Figure 7 shows the zone of inhibition produced by green and chemically synthesized $\mathrm{TiO}_{2}$ nanoparticles against both Gram-positive and Gram-negative bacterial strains. Pithecellobium dulce $\mathrm{TiO}_{2}$ nanoparticles exhibited maximum $(14 \mathrm{~mm})$ bacterial growth inhibition against $\mathrm{B}$. subtilis and Lagenaria siceraria $\mathrm{TiO}_{2}$ nanoparticles exhibited maximum $(11 \mathrm{~mm})$ bacterial growth inhibition against B. subtilis, in the form of zone-of-inhibition studies, where diffusion of nanoparticles on nutrient agar plates inhibits growth. In contrast, chemically synthesized $\mathrm{TiO}_{2}$ nanoparticles showed zones of inhibition of $12 \mathrm{~mm}$ against $\mathrm{B}$. subtilis. In the case of E. coli maximum growth, inhibition zones were found to be the following; 19, 17, and $14 \mathrm{~mm}$ for Pithecellobium dulce, Lagenaria siceraria leaf extract, and chemical synthesized $\mathrm{TiO}_{2}$ respectively (Figure $7 \&$ Table 1). Similar patterns were observed in the case of P. aeruginosa, Streptococcus pyogenes and S. aureus, where the maximum zone of inhibition was exhibited by Pithecellobium dulce followed by Lagenaria siceraria and $\mathrm{Chemical} \mathrm{TiO}_{2}$.. It appears that the antibacterial activity of the nanomaterials increased with increase in surface-to-volume ratio due to the decrease in size of nanoparticles. 

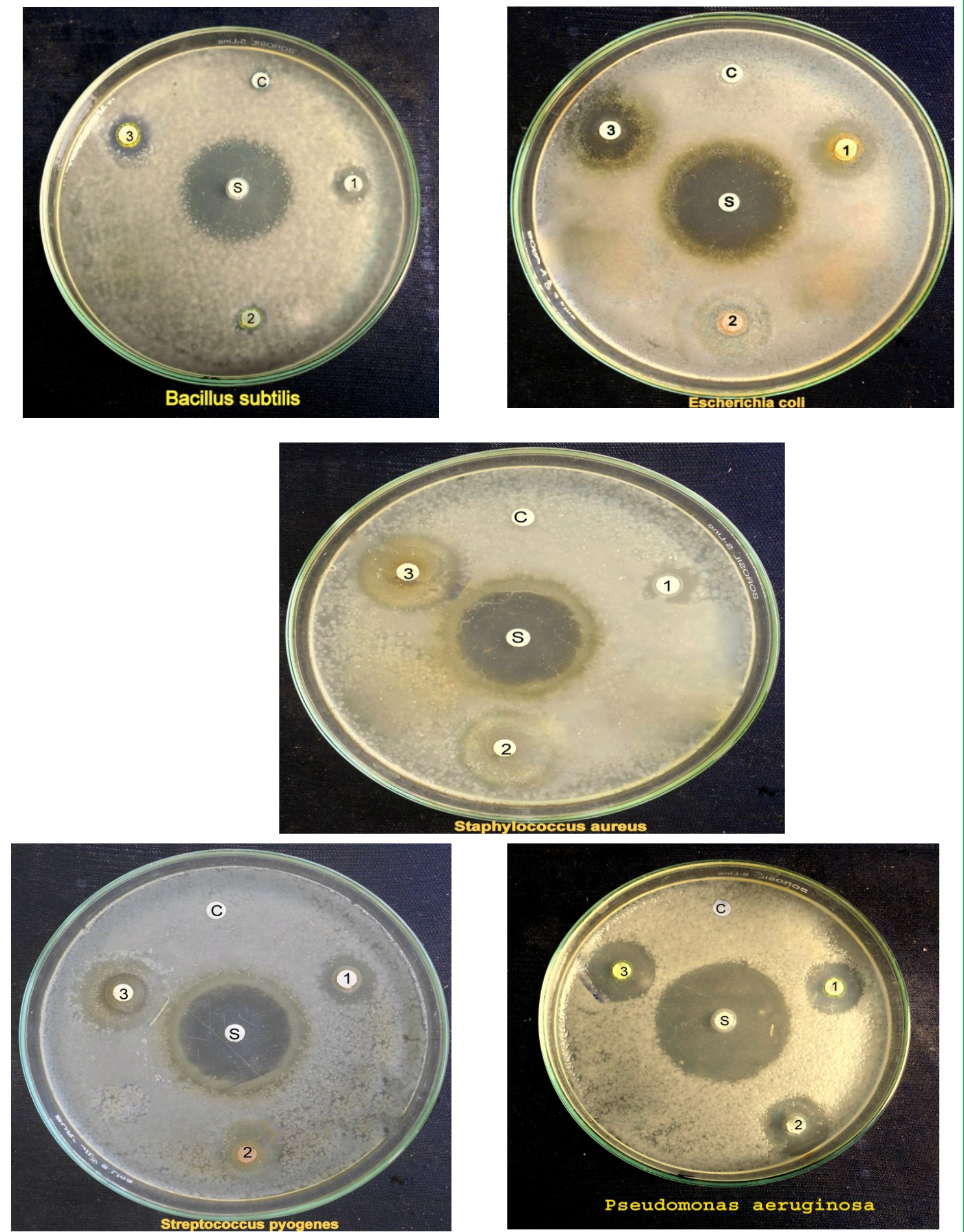

Figure 7: The antibacterial effect of (3) Pithecellobium dulce leaf Extract synthesized $\mathrm{TiO}_{2}(2)$ Lagenaria siceraria leaf Extract synthesized $\mathrm{TiO}_{2}(1)$ Chemically synthesized $\mathrm{TiO}_{2}$ 


\section{DPPH radical scavenging activity}

Free radical is unstable atoms or molecules with outer most electrons unpaired and it is highly reactive. The free radicals always strive to form stable bond, due to gaining or losing of an unpaired electron. DPPH is a stable compound and it will be reduced by accepting the hydrogen or electrons. The reducing activity of $\mathrm{TiO}_{2}$ nanoparticles synthesized from chemical and leaf extract of Pithecellobium dulce and Lagenaria siceraria was quantified spectrophotometrically by changing the DPPH color from purple to yellow. Percent of inhibition of DPPH radical scavenging activity was presented on Table 2. The DPPH activity of the $\mathrm{TiO}_{2}$ nanoparticles synthesized from green and chemical method were found to increase in a dose dependent manner. The DPPH radical scavenging activities were $19.02 \pm 0.52,28.76 \pm 0.15$ and $37.56 \pm 0.60 \%$ in 50,100 and $150 \mu \mathrm{L}$ for chemically synthesized $\mathrm{TiO}_{2}$ nanoparticles and $31.18 \pm 0.42,45.48 \pm 0.19$ and $58.20 \pm 0.25 \%$ in 50, 100 and $150 \mu \mathrm{L}$ for Lagenaria siceraria mediated synthesized $\mathrm{TiO}_{2}$ nanoparticles whereas value obtained $40.78 \pm 0.57,53.68 \pm 0.49$, and $65.57 \pm 0.32 \%$ in 50,100 and $150 \mu \mathrm{L}$ for Pithecellobium dulce mediated $\mathrm{TiO}_{2}$ nanoparticles, respectively. The results obtained in the DPPH assay showed effective free radical inhibition by chemically and biosynthesized $\mathrm{TiO}_{2}$ nanoparticles. The average percentage inhibition of Pithecellobium dulce mediated synthesized $\mathrm{TiO}_{2}$ nanoparticles was showed maximum of $52 \%$ as compared to that of chemically synthesized $\mathrm{TiO}_{2}$ nanoparticles and Lagenaria siceraria synthesized $\mathrm{TiO}_{2}$ nanoparticles $(26 \%$ and $45 \%)$ at different concentrations used in this study and the activity increased with increasing concentrations of $\mathrm{TiO}_{2}$ nanoparticles. The radical scavenging potential is dependent on various factors such as particle size, morphology, defects etc. Thus, the antioxidant assays suggest that Pithecellobium dulce and Lagenaria siceraria mediated synthesized $\mathrm{TiO}_{2}$ nanoparticles are good radical scavengers than chemically synthesized $\mathrm{TiO}_{2}$ nanoparticles due to decrease particle size and increase surface area. The free radical scavenging activity is a surface reaction since only the surface comes in contact with the free radicals.

Table - 1

Antibacterial activity [disc diffusion method]

\begin{tabular}{|c|l|c|c|c|c|c|}
\hline \multirow{2}{*}{ S. No. } & \multirow{2}{*}{ Bacteria } & \multirow{2}{*}{$\begin{array}{c}\text { Standard } \\
\text { Antibiotic } \\
\text { Disk* }\end{array}$} & & \multicolumn{4}{|c|}{ Zone of inhibition (mm) } \\
\cline { 4 - 7 } & & $\begin{array}{l}\text { Chemical } \\
\text { Method } \\
\text { TiO }\end{array}$ & $\begin{array}{c}\text { L. siceraria } \\
\text { TiO }_{2}\end{array}$ & ${\text { P.dulce } \text { TiO }_{2}}$ & Control DMSO \\
\hline 1 & Bacillus subtilis & 25 & 12 & 11 & 14 & - \\
\hline 2 & Escherichia coli & 25 & 14 & 17 & 19 & - \\
\hline 3 & $\begin{array}{l}\text { Pseudomonas } \\
\text { aeruginosa }\end{array}$ & 31 & 13 & 15 & 17 & - \\
\hline 4 & $\begin{array}{l}\text { Staphylococcus } \\
\text { aureus }\end{array}$ & 28 & 11 & 16 & 19 & \\
\hline 5 & $\begin{array}{l}\text { Streptococcus } \\
\text { pyogenes }\end{array}$ & 28 & 12 & 15 & 18 & \\
\hline
\end{tabular}

*ciprofloxacin 
Table - 2

Antioxidant activity of Pithecellobium dulce leaf Extract synthesized $\mathrm{TiO}_{2}$, Lagenaria siceraria leaf Extract synthesized $\mathrm{TiO}_{2}$ and Chemically synthesized $\mathrm{TiO}_{2}$

\begin{tabular}{|l|l|l|l|l|}
\hline $\begin{array}{l}\text { s. } \\
\text { no }\end{array}$ & $\begin{array}{l}\text { Concentrations } \\
(\mu \mathrm{L})\end{array}$ & $\begin{array}{l}\text { chemically } \\
\text { synthesized } \mathrm{TiO}_{2} \\
\text { nanoparticles }\end{array}$ & $\begin{array}{l}\text { Lagenaria siceraria } \\
\text { mediated synthesized } \\
\mathrm{TiO}_{2} \text { nanoparticles }\end{array}$ & $\begin{array}{l}\text { Pithecellobium dulce } \\
\text { mediated } \mathrm{TiO}_{2} \\
\text { nanoparticles }\end{array}$ \\
\hline 1 & $50 \mu \mathrm{L}$ & $19.02 \pm 0.52$ & $31.18 \pm 0.42$ & $40.78 \pm 0.57$ \\
\hline 2 & $100 \mu \mathrm{L}$ & $28.76 \pm 0.15$ & $45.48 \pm 0.19$ & $53.68 \pm 0.49$ \\
\hline 3 & $150 \mu \mathrm{L}$ & $37.56 \pm 0.60$ & $58.20 \pm 0.25$ & $65.57 \pm 0.32$ \\
\hline
\end{tabular}

\section{CONCLUSION}

In this study we have prepared $\mathrm{TiO}_{2}$ nanoparticles by using leaf extract of Pithecellobium dulce and Lagenaria siceraria and by a chemical method. Both nanoparticles were characterized for their size, and crystallinity using XRD, FTIR and SEM. The $\mathrm{TiO}_{2}$ nanoparticles which was capped and stabilized by phenolic and amine moieties of leaf extract was found to be lesser in size and more dispersed than the $\mathrm{TiO}_{2}$ nanoparticles prepared by chemical method. Moreover the leaf extract prepared $\mathrm{TiO}_{2}$ nanoparticles exhibited considerable antimicrobial activity against pathogenic bacteria, which is comparable with that of standard antibiotic and also perform antioxidant activity showed green synthesized $\mathrm{TiO}_{2}$ nanoparticles were effective free radical inhibition than chemically synthesized $\mathrm{TiO}_{2}$ nanoparticles. Based on these results we conclude that the leaf extract-stabilized $\mathrm{TiO}_{2}$ nanoparticles may have potential biomedical applications when compared to chemically synthesized $\mathrm{TiO}_{2}$ nanoparticles due to its enhanced dispersibility, stability and surface coatings.

\section{Reference}

[1] A. L. Barry., The antimicrobial susceptibility test. Principle and Practice, Lea and Febiger, Philadelphia, 180 (1976).

[2] Archana Maurya, Pratima Chauhan, Amita Mishra, and Abhay K. Pandey, Surface functionalization of $\mathrm{TiO} 2$ with plant extracts and their combined antimicrobial activities against E. Faecalis and E. Coli, Journal of Research Updates in Polymer Science, 1, 4351(2012).

[3] Blois, M.S., 1958. Antioxidant determinations by the use of a stable free radical. Nature. 29:1199 1200.

[4] D. Bhattacharya and R. K. Gupta, "Nanotechnology and potential of microorganisms," Critical Reviews in Biotechnology, vol. 25, no. 4, pp. 199-204, 2005.

[5] D. Goodsell, Bionanotechnology: Lessons from Nature, Willey- Less, New Jersey, NJ, USA, 2004.

[6] Deshpande, J.R., A.A. Choudhari, M.R. Mishra, V.S. Meghre, S.G. Wadodkar and A.K. Dorle, 2008. Beneficial effects of Lagenaria siceraria (Mol.) Standley fruit epicarp in animal models. Indian J. Exp. Biol., 46: 234-242.

[7] H.W. Seely and P. J. Van Demark., A Laboratory Manual of Microbiology, Taraporewala Sons and Co., Mumbai, 55 (1975).

[8] Kathiresan K, Asmathunisha N (2013) A review on biosynthesis of nanoparticles by marine organisms. Coll Surf B 103:283-287

[9] Kumar CG, Mamidyala SK. Extracellular synthesis of silver nanoparticles using culture suspernatat of Pseudomonas aeruginosa. Colloids and Surfaces B:Biointerfaces. 2011; 80:462-466. 
[10] M. C. Daniel and D. Astruc, "Gold nanoparticles: assembly, supramolecular chemistry, quantum-size-related properties, and applications toward biology, catalysis, and nanotechnology," Chemical Reviews, vol. 104, no. 1, pp. 293-346, 2004.

[11] M. Sundrarajan et al, Green synthesis of titanium dioxide nanoparticles by nyctanthes arbortristis leaves extract Chalcogenide Letters Vol. 8, No. 8, August 2011, p. 447-451

[12] Mahdavi M, Namvar F, Bin Ahmad M, Mohamad R. Green biosynthesis and characterization of magnetic iron oxide(Fe3O4) Nanoparticles using seaweed (Sargassum muticum)Aqueous Extract. Molecules 2013; 18:5954-5964.

[13] Naheed Ahmad and Seema Sharma, Green Synthesis of Silver Nanoparticles Using Extracts of Ananascomosus, Green and Sustainable Chemistry, 2, 141-147(2012).

[14] O. V. Salata, "Applications of nanoparticles in biology and medicine," Journal of Nanobiotechnology, vol. 2, no. 1, article 3, 2004.

[15] R. Paull, J. Wolfe, P. H'ebert, and M. Sinkula, "Investing in nanotechnology," Nature Biotechnology, vol. 21, no. 10, pp. 1144- 1147, 2003.

[16] Rodriques AG, Ping LY, Marcato PD, Alves OL, Silva MCP, Ruiz RC, Melo IS, Tasic L, DeSouza AO. Biogenic antimicrobial silver nanoparticles produced by fungi. Applied Microbiology Biotechnology. 2012; DOI:10.1007/00253-012-4209-7.

[17] Thiyagarajan Devasena et al, Comparative Studies on Green Synthesized and Chemically Synthesized Titanium Oxide Nanoparticles. A Validation for Green Synthesis Protocol using Hibiscus FlowerJ. Environ. Nanotechnol., Vol. 3(4), 78-85, (2014)

[18] Vijayalakshmi, R. and Rajendran, V., Synthesis and characterization of nano-TiO2 via different methods, Arch of App Sci Res., 4, 1183-1190(2012). 